Article

\title{
Estimation of the Timber Quality of Scots Pine with Terrestrial Laser Scanning
}

Ville Kankare $^{1,2, *}$, Marianna Joensuu ${ }^{1}$, Jari Vauhkonen ${ }^{1,2,3}$, Markus Holopainen ${ }^{1,2}$, Topi Tanhuanpää ${ }^{1,2}$, Mikko Vastaranta ${ }^{1,2}$, Juha Hyyppä ${ }^{2,4}$, Hannu Hyyppä ${ }^{2,5,6}$, Petteri Alho ${ }^{2,5,7}$, Juha Rikala ${ }^{1}$ and Marketta Sipi ${ }^{1}$

1 Department of Forest Sciences, University of Helsinki, FI-00014 Helsinki, Finland; E-Mails: marianna.joensuu@alumni.helsinki.fi (M.J.); jari.vauhkonen@helsinki.fi (J.V.); markus.holopainen@helsinki.fi (M.H.); topi.tanhuanpaa@helsinki.fi (T.T.); mikko.vastaranta@helsinki.fi (M.V.); juha.rikala@helsinki.fi (J.R.); marketta.sipi@helsinki.fi (M.S.) Centre of Excellence in Laser Scanning Research, Finnish Geodetic Institute, FI-02431 Masala, Finland School of Forest Sciences, University of Eastern Finland, FI-80101 Joensuu, Finland; E-Mail: jari.vauhkonen@uef.fi

4 Department of Remote Sensing and Photogrammetry, Finnish Geodetic Institute, FI-02431 Masala, Finland; E-Mail: juha.hyyppa@fgi.fi

5 Department of Real Estate, Planning and Geoinformatics, Aalto University, FI-00076 Aalto, Finland; E-Mails: hannu.hyyppa@aalto.fi (H.H.); petteri.alho@aalto.fi (P.A.)

6 Civil Engineering and Building Services, Helsinki Metropolia, University of Applied Sciences, FI-00079 Helsinki, Finland

7 Department of Geography and Geology, University of Turku, FI-20014 Turku, Finland

* Author to whom correspondence should be addressed; E-Mail: ville.kankare@helsinki.fi; Tel.: +358-409-669-109.

Received: 3 March 2014; in revised form: 1 July 2014 / Accepted: 23 July 2014 / Published: 31 July 2014

Abstract: Preharvest information on the quality of Scots pine (Pinus sylvestris) timber is required by the forest industry in Nordic countries, due to the strong association between the technical quality and product recovery of this species in particular. The objective of this study was to assess the accuracy of estimating external quality attributes and classifying the quality of mature Scots pine trees by terrestrial laser scanning (TLS). The tree quality was estimated using a random forest approach, based on both field and TLS measurements of stem diameters, tree height and branch heights. The relative root mean squared errors of the TLS measurements for tree height, diameter, diameter at $6 \mathrm{~m}$ and the lowest living and 
dead branch height were $7.1 \%, 5.9 \%, 8.9 \%, 9.6 \%$ and $42.9 \%$, respectively. The highest errors of the branch heights were caused by the shadowing effect in the point cloud data. The quality classes were estimated accurately, based on both (field and TLS measured) tree attributes. Trees were classified with $95.0 \%$ and $83.6 \%$ accuracy into three operationally-important quality classes and with $87.1 \%$ and $76.4 \%$ accuracy into five classes using, field or TLS measurements, respectively. The obtained quality classification results were promising. The enhanced tree quality information could have a significant effect on planning forest management procedures, wood supply chains and optimizing the flow of raw materials. To fully integrate tree quality measurements in operational forestry, the methods used should be fully automated.

Keywords: remote sensing; forest inventory; GIS; forest management planning; laser scanning; terrestrial laser scanning; timber quality; forest technology

\section{Introduction}

Information on the quality of available timber is an essential input for wood procurement planning, because the technical quality of standing timber directly affects the production potential and its value in the forest industry [1]. In the Nordic countries, the quality of Scots pine (Pinus sylvestris L.) trees is of particular interest, since the quality of this species and its effects on product recovery can be somewhat estimated based on external tree properties [2]. The most influential quality factors are the stem form, the heights of the lowest living $(l b)$ and dead branches $(d b)$ and the branch size distribution (diameter, location and number of branches) (e.g., [2,3]), of which the branch size distribution has the most pronounced effect on timber quality [4]. Bucking of the tree stems is affected by the lengths of the branchless trunk section, dead branch section and living crown. Quality attributes are currently measured only in specific sample-based inventories, and they are not available for forest management, due to the high costs of the fieldwork required. Therefore, the information available does not fully support demand-based wood procurement.

New technologies for forest inventorying have been developed rapidly in the last decade. Laser scanning-based applications have been widely studied (e.g., [5-7]) and are already in operational use [8-12]. Airborne laser scanning (ALS) has been used to estimate forest structural parameters from single trees (e.g., tree species, height $(\mathrm{H})$, diameter-at-breast height $(d b h)$ and volume $(v))$ to area levels (stand-level mean characteristics) [13-17]. Stand attribute information is conventionally estimated to a certain area level, based on large numbers of field sample plots, predictors derived from ALS data and statistical models linking field plots and ALS-derived predictors. With ALS data, this stand attribute estimation process is often called an area-based approach (ABA), e.g., [18]. Fixed-position (mounted on a tripod) terrestrial laser scanners offer a high potential for three-dimensional (3D) mapping of smaller areas or individual trees in high detail. Terrestrial laser scanning (TLS) is seen as an efficient and objective option for acquiring accurate field data to be used, e.g., with ABA (e.g., [19,20]).

TLS has been used for detailed modeling of individual trees and canopy (e.g., [21]). Previously, TLS has been capable of measuring tree characteristics, such as $d b h, h$, location and biomass [22-26]. 
Most importantly, TLS provides detailed information on stem taper and branch size distribution. The same level of detail cannot be achieved by any conventional field measurements [21-29]. The challenge in the use of TLS is the data processing, which should be fully automatized. Automatic data processing has been studied intensively, and promising algorithms have been developed (e.g., [7]). One practical consideration is that the forest structure (visibility at ground level) significantly affects the accuracy of TLS measurements [25,30].

ALS and TLS have previously been used to estimate tree quality properties, such as crown base heights at the level of individual trees (e.g., [31]) or plots [32], $d b$ [31], branch size distribution (e.g., [21]) and stem form (taper, sweep and lean) [29,33]. Kretschmer et al. [34] proposed an approach to measure external bark characteristics, based on TLS, while Stängle et al. [35] linked these measurements with the internal quality of logs, as determined by X-ray computer tomography. A strong correlation was reported between external branch scar measurements, based on TLS and inner wood quality [35].

Further, van Leeuwen et al. [36] reviewed standing wood and fiber quality attributes (e.g., fiber length and wood density) potentially measurable by laser-scanning methods. Hilker et al. [37] investigated the use of forest canopy- and topography-related characteristics derived from ALS to predict wood fiber properties and indicated that ALS-derived characteristics can potentially be used to predict wood fiber properties. Hilker et al. [37] and Luther et al. [38] proposed that forest structural variables extracted from area-based ALS data could explain $20 \%-50 \%$ of the variation observed in wood density and fiber attributes. Hilker et al. [37] concluded that ALS could also provide important tools for broader-scale wood quantity and quality characterization.

The applications and capabilities to measure or estimate various tree quality properties, e.g., stem curvature, branch distributions or stem damage, vary between the laser scanning techniques used. ALS measures various crown-level properties (cf. [39]), which can be related to the heights of the living crowns with an uncertainty of $1 \mathrm{~m}$ at best (see [40]). No direct information on the branch type (living or dead), stem attributes or defects can, however, be obtained.

The objective of this study was to assess the accuracy of tree quality estimation of Scots pine using attributes measured from TLS-point clouds. Tree quality could be a viable addition to the traditionally measured tree attributes (e.g., $d b h$ and height). TLS allows detailed measurement of tree and stem attributes, but the accuracy of estimating particular quality properties has not been evaluated so far. The objectives in detail were: (1) to assess the accuracy of tree quality estimation using tree attributes measured from TLS; (2) to assess the accuracy of tree quality estimation, based on field measured attributes; and (3) to assess the accuracy of TLS-measured tree variables (e.g., $h, d b h, d b$ and $l b$ ). The quality estimation results were compared with the quality classification done in the field. The study focuses on the quality estimation accuracy of Scots pine, because the effect of quality defects has the highest impact on the usability of timber in the forest industry in Finland.

\section{Material and Methods}

\subsection{Study Area and Field Measurements}

The study area (Figure 1) was located in Evo, southern Finland $\left(61.19^{\circ} \mathrm{N}, 25.11^{\circ} \mathrm{E}\right)$. The area belongs to the southern boreal zone and comprises approximately 2,000 ha of mainly managed forest. 
The forest stand selected (Figure 1) was about 2 ha, and the main tree species was Scots pine. The site type of the stand was medium-rich mineral soil forest. The mean age of the pine trees was approximately 75 years, and the forest management history included thinnings and two fertilizations, which caused wide variations in quality. Traditional field measurements with clinometers and calipers were conducted for 140 trees selected from the study stand. The trees were marked and numbered in the field to ease identification from the TLS data. The $d b h$ was measured with steel calipers from two perpendicular directions and tree $h$ was measured with a Haglöf Vertex laser rangefinder (Haglöf Sweden AB, Långsele, Sweden), as were the $l b$ and $d b$. The diameter at 6-m height $\left(d_{6}\right)$ was measured to centimeter accuracy, using specially designed calipers, where a traditional diameter caliber is attached to a $6 \mathrm{~m}$-long pole. The ground level was used as the starting point for measuring the $1.3-\mathrm{m}$ and 6-m heights. The mean $h$ and $d b h$ of the sample trees were $24.8 \mathrm{~m}$ and $298.3 \mathrm{~mm}$, respectively. More detailed statistics of the sample trees are presented in Table 1.

Figure 1. The study area located in Evo, southern Finland $\left(61.19^{\circ} \mathrm{N}, 25.11^{\circ} \mathrm{E}\right)$.

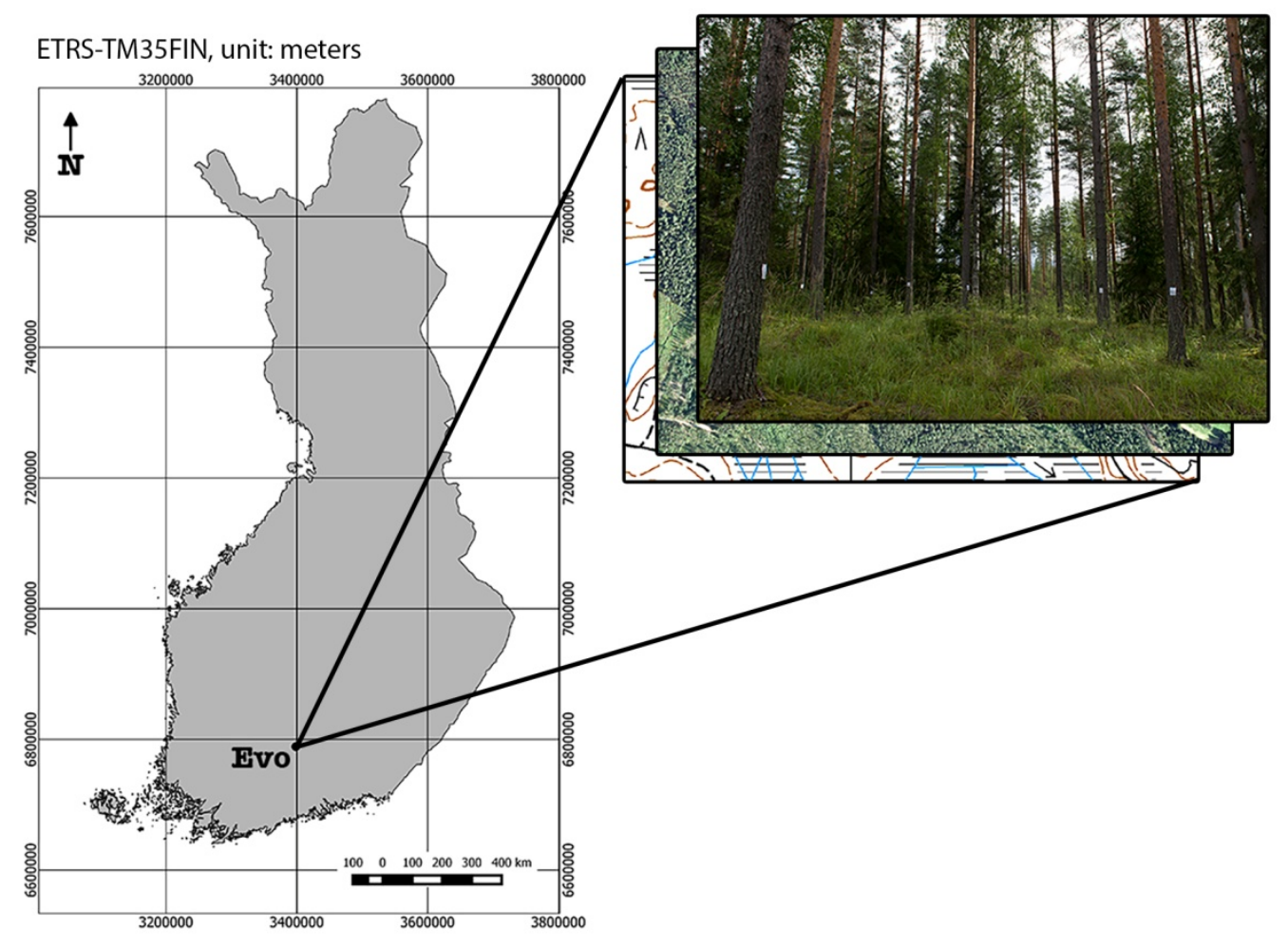

Table 1. Descriptive statistics of the field measurements. Abbreviations: diameter-at-breast height $(d b h)$, tree height $(h)$, diameter at 6-m height $\left(d_{6}\right)$, height of the lowest living $(l b)$ and dead $(d b)$ branch and tree volume $(v)$.

\begin{tabular}{ccccc}
\hline & Min & Mean & Max & SD \\
\hline$d b h, \mathrm{~mm}$ & 183.0 & 298.3 & 410.0 & 45.0 \\
$h, \mathrm{~m}$ & 22.4 & 24.8 & 28.1 & 1.4 \\
$d_{6}, \mathrm{~mm}$ & 130.0 & 241.5 & 350.0 & 42.1 \\
$l b, \mathrm{~m}$ & 10.2 & 14.5 & 17.9 & 1.9 \\
$d b, \mathrm{~m}$ & 2.3 & 5.2 & 10.5 & 1.9 \\
$v, \mathrm{dm}^{3}$ & 282.5 & 817.2 & $1,549.4$ & 259.9 \\
\hline
\end{tabular}


The following tree quality classes were recorded for the sample trees using ocular assessment (based on instructions of the National Forest Inventory (NFI) in Finland): (5) best-quality timber; the tree includes high-quality sawlogs and over $80 \%$ of the tree is saw wood; (6) damaged good-quality timber; the tree includes high-quality sawlogs, but less than $80 \%$ of the tree is saw wood; (7) timber; over $80 \%$ of the tree is saw wood, but without high-quality logs; (8) damaged timber; less than $80 \%$ of the tree is saw wood, and there are no high-quality logs; and (9)-quality timber (pulpwood); the tree is log size, but it does not fulfil the quality requirements for sawlogs. The tree quality class distributions are shown in Figure 2. These quality measurements for all of the 140 sample trees were used as a reference for quality estimations based on tree attributes measured either in the field or from the TLS data.

Figure 2. Reference tree quality distribution based on ocular assessment. Classes: (5) best-quality timber; (6) damaged good-quality timber; (7) timber; (8) damaged timber; and (9) low-quality timber (pulpwood).

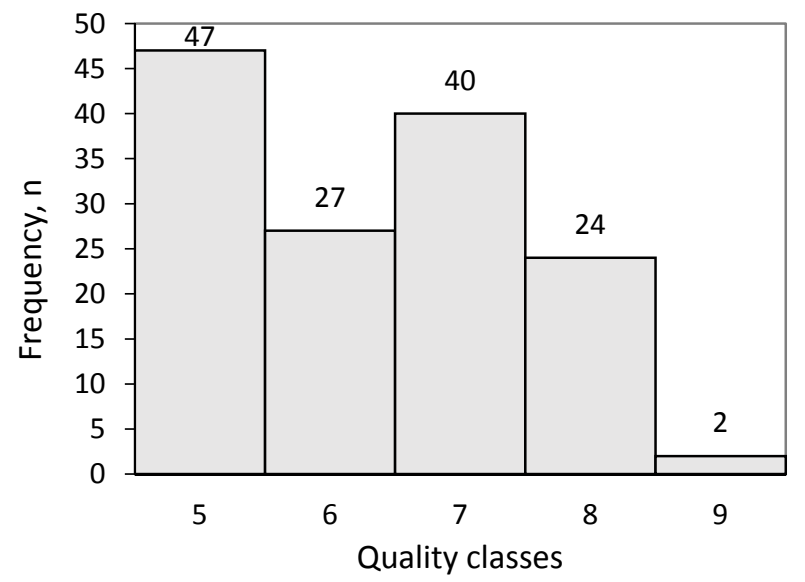

\subsection{Terrestrial Laser Scanning}

The TLS data were collected with a Leica HDS6100 TLS system (Leica Geosystems AG, Heerbrugg, Switzerland). The TLS scanner is a $690-\mathrm{nm}$, phase-based, continuous-wave laser scanner with a $360^{\circ} \times 310^{\circ}$ field-of-view, and its data acquisition rate is 508,000 points per second. The distance measurement accuracy is $2 \mathrm{~mm}$ at a distance of $25 \mathrm{~m}$. The point spacing is $6.3 \mathrm{~mm}$ at $10 \mathrm{~m}$ (with an angular resolution of $0.009^{\circ}$ ), which results in approximately 25,000 points per $\mathrm{m}^{2}$ at the same distance. More detailed specifications are presented in Table 2. In all, 45 scans were done to cover the entire stand and sample trees.

The TLS measurements of the stand and sample trees were collected in multi-scan mode (e.g., [26]). The TLS data were collected in four scan groups consisting of 10 or more scans per group. TLS point clouds within each group were coregistered, using reference targets (spheres). The reference targets are distributed in the sampling in the following manner: all of the targets are visible from the center scan, and at least three targets are visible from the rest of the scans. Coregistration was carried out with Z+F LaserControl 8.2 software (Zöller + Fföhlich $\mathrm{GmbH}$ ). The principle of co-registration is that spheres of constant size are fitted in the point clouds (reference targets), and the $3 \mathrm{D}$ transformation is then calculated between the point clouds. Coregistration was undertaken by 
searching these overlapping targets (spheres) from the point clouds, and the corresponding sphere pairs were used as constraints between point clouds. The software computes automatically the optimal alignment of the point clouds using these selected sphere constraints. The TLS data were georeferenced into the ETRS-TM35FIN coordinate system, using reference target locations and scan locations measured with a Global Positioning System (GPS). The GPS error was estimated to vary between 10 to $30 \mathrm{~cm}$. TLS points belonging to sample trees were extracted from the whole point cloud, using Terrascan software (Terrasolid, Helsinki, Finland). After point extraction, the following tree variables were measured from the tree-by-tree point clouds, using the same software: $d b h, h, l b, d b$ and $d_{6}$. Tree variables were measured manually using a distance measurement tool, which measures the distance between two points. The following procedure was used: (1) define ground level; (2) define 1.3-m and 6-m height from the ground level and measure diameters; (3) search and measure visually the height of the lowest living and dead branch; and (4) measure the tree height.

Table 2. Terrestrial laser scanning (TLS) data acquisition parameters.

\begin{tabular}{cc}
\hline & Leica HDS6100 \\
\hline Field of view & $310^{\circ} \times 360^{\circ}$ \\
Range & $79 \mathrm{~m}$ \\
Speed points per s & 508,000 \\
Spot size & $3 \mathrm{~mm}+0.22 \mathrm{mrad}$ \\
Distance measurement accuracy at $25 \mathrm{~m}$ & $\pm 2 \mathrm{~mm}$ \\
Max resolution, Horizontal $\times$ Vertical & $0.009^{\circ} \times 0.009^{\circ}$ \\
Max points $360^{\circ}$, Horizontal $\times$ Vertical & $40,000 \times 40,000$ \\
Laser wavelength & $690 \mathrm{~nm}$ \\
Laser power & $30 \mathrm{~mW}$ \\
\hline
\end{tabular}

\subsection{Tree Quality Estimation and Accuracy Assessment}

The following additional tree and canopy variables were calculated to assist in the quality estimation: crown ratio $(\mathrm{cr}, \%)$ as the ratio of the living canopy to the tree $h(1)$; dead branch trunk ratio ( $d r, \%)(2)$; and branchless trunk ratio $(b t, \%)$, describing the sections of the trunk without branches, respectively, in proportion to the length of the entire trunk (3). The equations are shown in detail below.

$$
\begin{gathered}
\text { Crown ratio }(c r, \%)=(h-l b) / h \\
\text { Dead branch trunk ratio }(d r, \%)=(l b-d b) / h \\
\text { Branchless trunk ratio }(b t, \%)=d b / h
\end{gathered}
$$

Tree quality was estimated for the sample trees, using a nearest neighbor (NN) approach. Tree quality was used as the response variable (y-value), and the tree variables measured from the field and TLS were used as predictors (x-values). With this procedure, we aim to investigate the accuracy of TLS-derived variables in the tree quality estimation compared to traditional field measured variables. Random forest (RF) was applied in the search for NNs. The use of the RF method for NN searching was explained by Crookston and Finley [41] and used by Hudak et al. [42] and Falkowski et al. [43] with remote sensing data. In order to gain a high level of consistency, a total of 1,000 regression trees were fitted in each RF run. Randomness was also taken into account by running the RF method 
100 times. The final result was the average of these runs. The $\mathrm{R}$ statistical computing environment [44] and yaImpute library [41] were applied in the RF predictions.

In addition to the NFI classification (five quality classes, Section 2.1), the classification accuracy was evaluated for an aggregated three-class case, in which the classes were: 1 (NFI Classes 5 and 6, high-quality timber); 2 (NFI Classes 7 and 8, low-quality timber) and 3 (NFI Class 9, pulpwood). The accuracies of predicting the categorical variables were evaluated in terms of overall accuracy (\%) calculated from the out-of-bag samples produced by the RF. The estimation of continuous variables was assessed in terms of bias and root-mean-squared errors (RMSEs).

\section{Results}

\subsection{Accuracy of the Tree Attributes Measured from TLS Data}

The accuracies (RMSE and bias) of the tree attributes measured from TLS data are shown in Table 3. The traditional field measurements were used as reference values in this validation. The tree $h$ values were mainly underestimated, as shown in Figure 3 (top left corner), with an RMSE of $1.8 \mathrm{~m}$. The $d b h$ and $d_{6}$ values were unbiased with RMSEs of $17.7 \mathrm{~mm}$ and $21.7 \mathrm{~mm}$, respectively. The $d b$ value had the highest RMSE of $2.2 \mathrm{~m}(43 \%)$, while the $l b$ was underestimated in most cases $(76.4 \%)$. The accuracies were highly affected by the visibility and the amount of points returned from the sample trees.

Table 3. Tree variable measurement accuracy from TLS data. Abbreviations: $d b h=$ diameter-at-breast height $(1.3 \mathrm{~m}), d_{6}=$ diameter at $6-\mathrm{m}$ height, $l b=$ height of the lowest living branch and $d b=$ height of the lowest dead branch.

\begin{tabular}{ccccc}
\hline & Bias & Bias \% & RMSE & RMSE \% \\
\hline$h, \mathrm{~m}$ & 1.4 & 5.6 & 1.8 & 7.1 \\
$d b h, \mathrm{~mm}$ & 6.6 & 2.2 & 17.7 & 5.9 \\
$d_{6}, \mathrm{~mm}$ & -1.6 & -0.7 & 21.7 & 8.9 \\
$l b, \mathrm{~m}$ & 0.6 & 4.4 & 1.4 & 9.6 \\
$d b, \mathrm{~m}$ & -0.3 & -6.3 & 2.2 & 42.9 \\
\hline
\end{tabular}

Figure 3. Field measured tree attributes (reference) against TLS measured tree attributes (estimated). The line represents a 1:1 relationship.

$h$

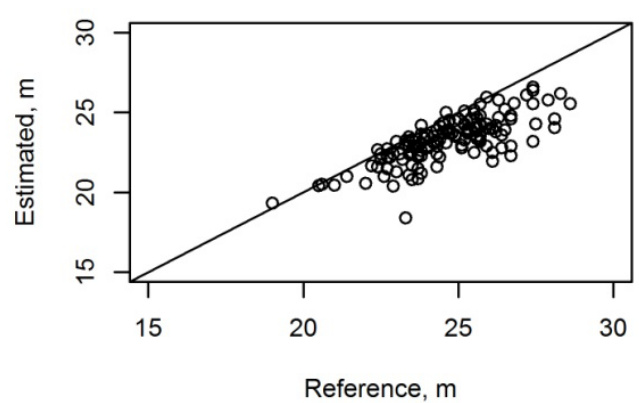

$d b h$

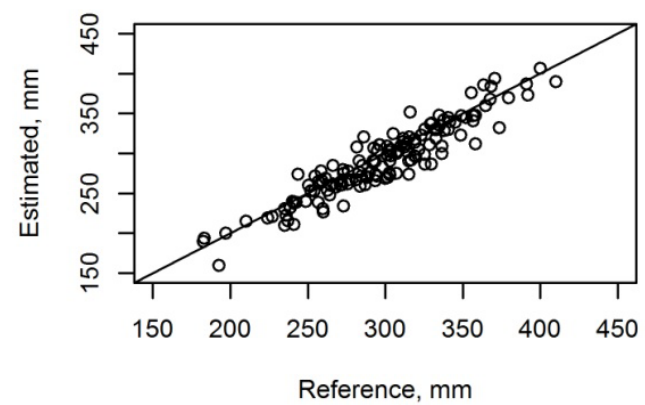


Figure 3. Cont.

Ib

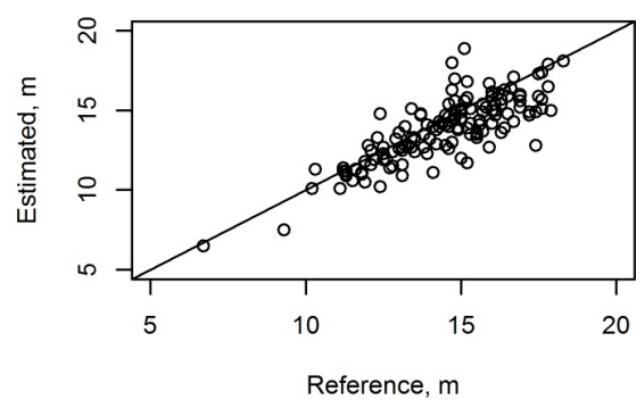

d6

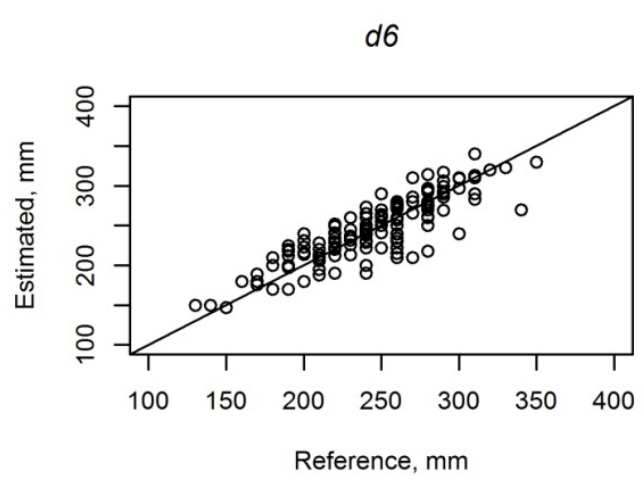

$d b$

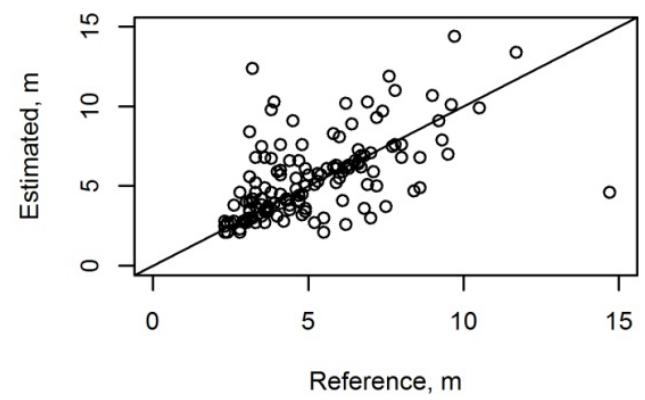

Reference, $m$

\subsection{Tree Quality Predicted Using RF}

Visual field observation (see Section 2.1) were used as a reference for tree quality predictions using TLS and field measured tree attributes (e.g., $d b h$ and branch heights) as explanatory variables. Tree quality was estimated via two different class partitionings: (1) in three quality classes; and (2) in five quality classes. The classification accuracies and confusion matrices are shown in Tables 4 and 5 . The overall accuracies of classifying the trees to three classes based on the field and TLS measurements were $95.0 \%$ and $83.6 \%$, respectively. The results showed that trees can be classified into aggregated timber quality classes accurately. The classification accuracies decreased when quality estimation was evaluated in five classes. When tree quality was predicted based on field measurements, the most important predictors for quality estimation were $d b$ and $b t$, whereas when based on TLS measurements, they were $d b, b t$ and $d b h$. Figure 4 shows the variation in different variables measured in the field within each quality class in the boxplot. The figure shows that high (Classes 5 and 6) and low-quality (Classes 7 to 9) classes can be differentiated, but more detailed classification is challenging. For example, there are only small differences with the tree variables used between Classes 5 and 6, e.g., with $d b$ (see Figure 4, top right corner). 
Table 4. Confusion matrix of three quality classes (reference vs. RF estimates), overall and class-level classification accuracies based on field (left) and TLS (right) measurements.

\begin{tabular}{|c|c|c|c|c|c|c|c|c|c|c|c|}
\hline & & \multicolumn{5}{|c|}{ Field Measurements } & \multicolumn{5}{|c|}{ TLS } \\
\hline & & \multicolumn{3}{|c|}{ Prediction } & \multirow{2}{*}{$\begin{array}{r}\text { Class-Level } \\
\text { Accuracy, \% }\end{array}$} & \multirow{2}{*}{ Overall Accuracy, $\%$} & \multicolumn{3}{|c|}{ Prediction } & \multirow{2}{*}{$\begin{array}{c}\text { Class-level } \\
\text { Accuracy, \% }\end{array}$} & \multirow{2}{*}{ Overall Accuracy, \% } \\
\hline & & 1 & 2 & 3 & & & 1 & 2 & 3 & & \\
\hline \multirow{3}{*}{ Reference } & 1 & 74 & 0 & 0 & 100.0 & 95.0 & 62 & 11 & 1 & 83.8 & 83.6 \\
\hline & 2 & 5 & 59 & 0 & 90.8 & & 9 & 55 & 0 & 84.6 & \\
\hline & 3 & 0 & 2 & 0 & 0.0 & & 1 & 1 & 0 & 0.0 & \\
\hline
\end{tabular}

Table 5. Confusion matrix of five quality classes (reference vs. RF estimates), overall and class-level classification accuracies based on field (left) and TLS (right) measurements.

\begin{tabular}{|c|c|c|c|c|c|c|c|c|c|c|c|c|c|c|c|}
\hline & & \multicolumn{7}{|c|}{ Field Measurements } & \multicolumn{7}{|c|}{ TLS } \\
\hline & & \multicolumn{5}{|c|}{ Prediction } & \multirow{2}{*}{$\begin{array}{c}\text { Class-Level } \\
\text { Accuracy, \% }\end{array}$} & \multirow{2}{*}{$\begin{array}{c}\text { Overall } \\
\text { Accuracy, \% }\end{array}$} & \multicolumn{5}{|c|}{ Prediction } & \multirow{2}{*}{$\begin{array}{l}\text { Class-Level } \\
\text { Accuracy, \% }\end{array}$} & \multirow{2}{*}{$\begin{array}{c}\text { Overall } \\
\text { Accuracy, \% }\end{array}$} \\
\hline & & 5 & 6 & 7 & 8 & 9 & & & 5 & 6 & 7 & 8 & 9 & & \\
\hline \multirow{5}{*}{ Reference } & 5 & 45 & 2 & 0 & 0 & 0 & 95.7 & 87.1 & 45 & 0 & 1 & 1 & 0 & 95.7 & 76.4 \\
\hline & 6 & 6 & 20 & 1 & 0 & 0 & 74.1 & & 3 & 16 & 5 & 2 & 1 & 59.3 & \\
\hline & 7 & 3 & 0 & 36 & 1 & 0 & 90.0 & & 3 & 3 & 33 & 1 & 0 & 82.5 & \\
\hline & 8 & 1 & 1 & 1 & 21 & 0 & 87.5 & & 3 & 1 & 7 & 13 & 0 & 54.2 & \\
\hline & 9 & 0 & 0 & 1 & 1 & 0 & 0.0 & & 0 & 1 & 1 & 0 & 0 & 0.0 & \\
\hline
\end{tabular}


Figure 4. Boxplots of the various field-measured explanatory variables used to estimate quality.

Ib

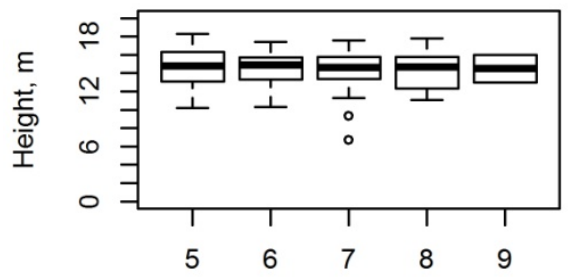

$\mathrm{Cr}$

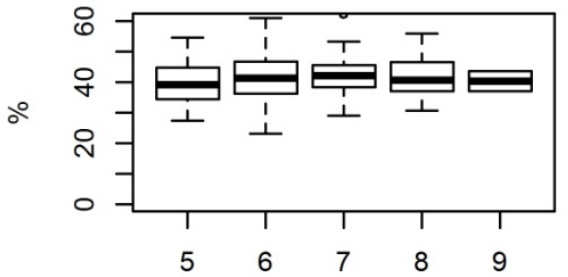

$b t$

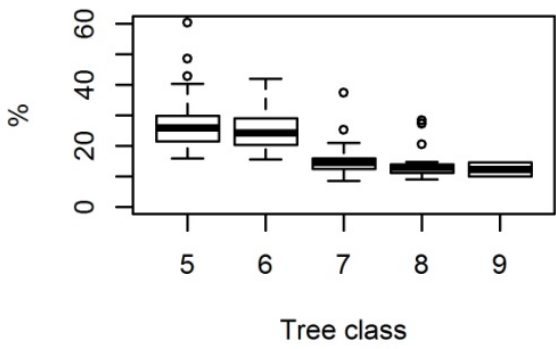

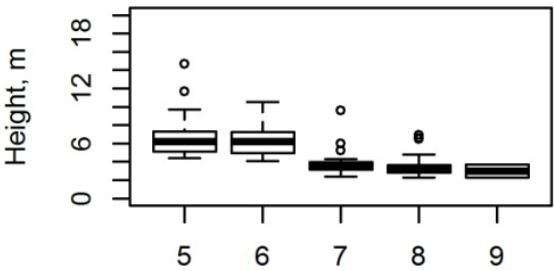

$d r$

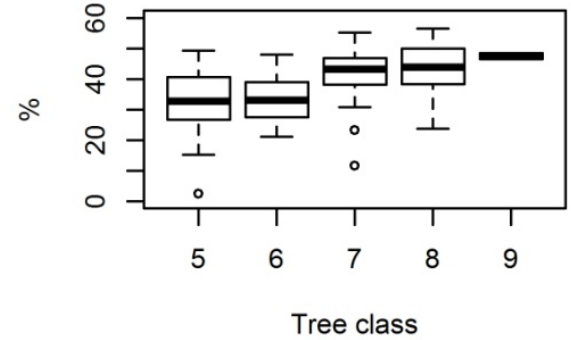

Tree quality estimation accuracy was also evaluated at the class level. The field-measured tree variables enabled high classification accuracies in RF tree quality estimation. Trees could be classified to the best-quality timber with $100 \%$ accuracy and to low-quality timber with $90.8 \%$ accuracy. Only the pulpwood class resulted in low accuracy, but it was mainly caused by the limited number of sample trees, only two, within this class. The TLS measurements resulted in slightly lower accuracies than did the field measurements.

The classification accuracies to five classes (NFI quality Classes 5-9) varied between 74.1\% and 95.7\% with field measurements and 54.2\% and 95.7\% with TLS (Table 5). The pulpwood class (9) accuracy was low with both measurements. The TLS measurements show lower classification accuracies with Classes 6 and 8 than the field measurements. Three trees were classified in the better class (5), and eight trees were classified in lower-quality classes (7-9). The confusion matrix in Table 5 shows that the field measurements mainly overestimated the tree quality class. Similar trends were not found with estimates based on the TLS measurements. 


\section{Discussion}

Precise knowledge of the quality of available timber plays an essential role in planning and managing the raw material flow from forest to final product. It significantly affects the total amount of income from timber sales [3]. It is more profitable for the forest owner to grow high-quality timber when the demand and the pricing methods support the real added value. There has been widespread discussion in the forest industry about the feasibility of modifying timber pricing more towards quality-based pricing (e.g., [45]). This could significantly affect the timber market and also the accuracy of required inventory information from the forests. Currently, tree quality attributes are not usually included in forest planning, due to the high cost of the fieldwork required. Therefore, the information available does not fulfil the requirements of a product-based wood supply chain.

TLS has been used for detailed modeling of individual tree and canopy characteristics, such as $d b h$, $h$, location and biomass (see, e.g., [22-26]). Most importantly, TLS provides more detailed information on stem taper and branch size distribution that cannot be achieved by any conventional field measurements. Tree quality could be a viable addition to the traditionally measured tree attributes (e.g., $d b h$ and height). The accuracy of estimating tree quality attributes has not been evaluated so far. Therefore, the objective of this study was to assess the accuracy of tree quality estimation of Scots pine. Tree quality was estimated, using attributes measured from TLS-point clouds. The study focused on the quality estimation accuracy of Scots pine, because the effect of quality defects for Scots pine has the highest impact on the usability of timber in the forest industry in Finland.

The accuracy of TLS-measured parameters (e.g., $h, d b h, l b$ and $d b$ ) were assessed. The $d b$ estimation accuracy (RMSE) was 42.9\% (2.2 m). The accuracy obtained here was lower than in [31]. The ALS estimation is based on an indirect relationship, and the accuracies therefore depend on the quality and extent of the reference database. The difference between the accuracies obtained in [31] and [40] indicate that it may be difficult to establish a database covering the full variation of $d b$ between the stands. Thus, the direct measurement of the raw TLS point cloud depicting the forest stand of interest should fundamentally improve the accuracy. The low accuracy of the $d b$ measurements here was mainly caused by the shadowing of the TLS-point cloud data, due to the dense understory layer in the stand. Normally, this understory layer of small trees would have been cleared before harvesting to ensure the efficiency and safety of the procedure. In all, the visibility is one of the most significant factors affecting the accuracy of TLS measurements.

Tree $d b h$ was estimated with the highest accuracy. These results are similar to those previously published (e.g., [26,29]). Liang et al. [28] showed that even more accurate $d b h$ estimation can be achieved using automatic stem curve measurements. The estimation accuracy of tree $h$ was also similar to that obtained in previous studies (e.g., $[26,29]$ ). Tree $h$ was systematically underestimated due to the limited visibility for the tip of the tree crown.

The results achieved here for the estimation of the external quality of timber are promising. The results show that a quality classification corresponding to the ocular assessment carried out in the NFI can be achieved in terms of the branch height features (95\% accuracy), and a closely corresponding result can be derived from the TLS measurements of these attributes. Trees were classified with $83.6 \%$ accuracy to three classes and $76.4 \%$ accuracy to five classes, using tree attributes measured from TLS data. The lower classification accuracy to five classes was caused mainly by the smaller difference in 
predictors, e.g., $d b$, between Classes 5 and 6 (see Figure 4). The quality differences were more clear (significant) if only three quality classes were used. The most important predictor was the $d b$, which is in line with previous studies (e.g., [4]). If the accuracies were evaluated by class, the highest classification accuracies would be found in Classes 5 and 7 (Table 5). The lowest accuracy (0\%) was found in Class 9. This was caused most likely by the small sample size (two trees), and therefore, to evaluate the tree quality classification accuracies further, a larger and more diverse dataset is required. Furthermore, the consistency of the ocular assessment of the tree quality measurements used as a reference has an effect on the estimation accuracies. Tree-level field measurements are highly dependent on the measurer and can vary significantly; therefore, it is important to evaluate the consistency and quality of the ocular assessment in future studies.

Tree attributes were measured manually from TLS-point clouds in the present study, which is a limiting factor. Manual measurements are not feasible to use in the wall-to-wall forest inventory of large areas, but they can be used effectively at a small scale. To bring these methods to operational forestry, data processing should be automatic, and there has already been many promising publications (e.g., [7,21]. However, further development and validation is required, because the accuracy is highly dependent on the sample data used. The accuracy of TLS and different data processing techniques should be investigated in various forest conditions.

The real quality and obtainable final products of harvested timber are determined in the factory, based on the internal structure of the logs. A nondestructive method is used to gain information on the internal structure of logs. This information is provided by on-line applications in sawmills in Finland, using 3D or X-ray log-scanning methodologies. Sawmills use 3D scanners or X-ray log scanners to sort logs into different quality classes $([46,47])$. These scanners give information on the general knot structure for an entire log. The information gained could be useful for developing and testing novel timber quality models that could be applied at all stages of wood production and the supply chain. The possible link between industrial 3D and X-ray scanning and TLS or ALS should be investigated further.

The forest management decision-support systems that are currently used are based on more generalized information (e.g., forest attribute information estimated by the ABA), which may result in difficulties in distinguishing possible stands for management and prioritizing them (e.g., [48,49]). The decision-support system needed in the Nordic cut-to-length method requires detailed preharvest information [49]. The three most important preharvest information attributes mentioned were: (1) tree species distribution; (2) stem distribution; and (3) quality [48,49]. Preharvest information is used to allocate specific timber assortments required for raw materials and to plan harvesting operations to fulfill production needs [49]. This type of detailed preharvest information is not used commonly in practice. The use of ALS as a basis for the decision-support system has frequently been studied, e.g., by [48-51]. Vauhkonen et al. [49] concluded that the decision-support system proposed could be used for ranking possible stands only by timber quantity, not timber quality. ALS data are seen as inadequate to measure or estimate timber quality attributes in detail. Vauhkonen et al. [49] suggested that TLS could be better used as input in the decision-support system if quality attributes are taken into account, which was demonstrated, e.g., in [52], with promising results compared to forest inventory methods in forest plantations in Australia. 


\section{Conclusions}

TLS measurements offer a new approach to derive precise information on standing trees, which can be utilized in forestry application and forest management procedures. Tree quality attributes can be measured in addition to traditionally measured parameters accurately from dense 3D point clouds. TLS enables more detailed measurements from standing trees (e.g., stem curve or branch distributions) than is feasible to measure with traditional means. This study showed the first results on external tree quality estimation using TLS data. The quality classification accuracies were high, based on both datasets (field or TLS measurements). The trees were classified with $95.0 \%$ and $83.6 \%$ accuracy into three classes and with $87.1 \%$ and $76.4 \%$ accuracy into five classes using field-measured or TLS-measured features, respectively. The higher error with $d b$ was caused by the shadowing effect of the dense understory vegetation. The accuracy will increase if the understory vegetation would have been cleared before the TLS. Results have shown that the accuracy of $d b$ measurement significantly affects the quality classification results. The tree quality classification results achieved were promising, but further evaluation of the method is required with more and more diverse sample data. The small sample size, especially with Class 9, is a limiting factor in the present study, and it should be further investigated. Tree quality information would significantly affect the planning of forest management procedures, wood supply chain and optimizing the flow of raw materials. An important development subject is the automation of the tree quality measurements, and promising methods have already been published; e.g., [21]. The measurement procedure should be fully automatic before it can be used in operational forestry. A combination of ALS, TLS and also mobile laser scanning (MLS) could be a viable option in tree quality estimation (e.g., [53]).

\section{Acknowledgments}

This study was commissioned by Metsäteho Oy and Metsägroup Oy and was made possible by financial aid from Metsägroup $\mathrm{Oy}$, Metsämiesten säätiö, Finnish Academy project Centre of Excellence in Laser Scanning Research (CoE-LaSR, Decision Number 272195) and the Finnish Academy project ‘Science and Technology Towards Precision Forestry' (PreciseFor).

\section{Author Contributions}

Ville Kankare was the lead author of the article and made the analyses with Marianna Joensuu. Marianna Joensuu was responsible for the field data collection with Ville Kankare. The article was improved by the contributions of all of the co-authors at various stages of the analysis and writing process.

\section{Conflicts of Interest}

The authors declare no conflict of interest. 


\section{References}

1. Lukkarinen, E.; Keskinen, S.; Pennanen, O. Tukkien laatukriteerit ja apteerauksen arvoperusteet. Metsätehon Rap. 1998, 65, 34.

2. Uusitalo, J. Pre-harvest measurement of pine stands for sawing production planning. Acta For. Fenn. 1997, 259, 56.

3. Hujo, S.; Poikela, A. Puutavaralajien laatuvaatimukset. In Book Tapion Taskukirja, 25th ed.; Rantala, S., Ed.; Metsäkustannus Oy and Metsätalouden kehittämiskeskus: Tapio, Finland, 2008; pp. 379-383.

4. Suomen Sahateollisuusmiesten Yhdistys (STMY). Mänty-ja kuusisahatavaran lajitteluohjeet. In Book Pohjoismainen Sahatavara-Lajitteluohjeet, 1st ed.; Gummerus Kirjapaino Oy: Jyväskylä, Finland, 1994; p. 64.

5. Hyyppä, J.; Hyyppä, H.; Leckie, D.; Gougeon, F.; Yu, X.; Maltamo, M. Review of methods of small-footprint airborne laser scanning for extracting forest inventory data in boreal forests. Int. J. Remote Sens. 2008, 29, 1339-1366.

6. McRoberts, R.E.; Tomppo, E.; Næsset, E. Advances and emerging issues in national forest inventories. Scand. J. For. Res. 2010, 25, 368-381.

7. Liang, X. Feasibility of Terrestrial Laser Scanning for Plotwise Forest Inventories. Ph.D. Thesis, Publication of the Finnish Geodetic Institute, Masala, Finland, 2013; Volume 149, p. 55.

8. Holopainen, M.; Vastaranta, M.; Liang, X.; Hyyppä, J.; Jaakkola, A.; Kankare, V. Estimation of forest stock and yield using LiDAR data. In Remote Sensing of Natural Resources; Wang, G., Weng, Q., Eds.; CRC Press: Boca Raton, FL, USA, 2013; pp. 259-290.

9. Næsset, E. Airborne laser scanning as a method in operational forest inventory: Status of accuracy assessments accomplished in Scandinavia. Scand. J. For. Res. 2007, 22, 433-442.

10. Maltamo, M.; Packalén, P.; Kallio, E.; Kanga, J.; Uuttera, J.; Heikkilä, J. Airborne laser scanning based stand level management inventory in Finland. In Proceedings of the Silvilaser Conference, Hobart, TS, Australia, 16-19 October 2011.

11. Vastaranta, M. Forest Mapping and Monitoring Using Active 3D Remote Sensing. Ph.D. Thesis, University of Helsinki, Helsinki, Finland, 2012; Volume 144, p. 45.

12. White, J.; Wulder, M.; Vastaranta, M.; Coops, N.; Pitt, D.; Woods, M. The utility of image-based point clouds for forest inventory: A comparison with airborne laser scanning. Forests 2013, $4,518-536$.

13. Holopainen, M.; Vastaranta, M.; Rasinmäki, J.; Kalliovirta, J.; Mäkinen, A.; Haapanen, R.; Melkas, T.; Yu, X.; Hyyppä, J. Uncertainty in timber assortment estimates predicted from forest inventory data. Eur. J. For. Res. 2010, 129, 1131-1142.

14. Hyyppä, J.; Yu, X.; Hyyppä, H.; Vastaranta, M.; Holopainen, M.; Kukko, A.; Kaartinen, H.; Jaakkola, A.; Vaaja, M.; Koskinen, J. Advances in forest inventory using airborne laser scanning. Remote Sens. 2012, 4, 1190-1207.

15. Vastaranta, M.; Kankare, V.; Holopainen, M.; Yu, X.; Hyyppä, J.; Hyyppä, H. Combination of individual tree detection and area-based approach in imputation of forest variables using airborne laser data. ISPRS J. Photogr. Remote Sens. 2012, 67, 73-79. 
16. Yu, X.; Hyyppä, J.; Vastaranta, M.; Holopainen, M.; Viitala, R. Predicting individual tree attributes from airborne laser point clouds based on the random forests technique. ISPRS J. Photogr. Remote Sens. 2011, 66, 28-37.

17. Ko, C.; Sohn, G.; Remmel, T.K. Tree genera classification with geometric features from high-density airborne LiDAR. Can. J. Remote Sens. 2013, 39, 73-85.

18. Næsset, E. Predicting forest stand characteristics with airborne scanning laser using a practical two-stage procedure and field data. Remote Sens. Environ. 2002, 80, 88-99.

19. Liang, X.; Litkey, P.; Hyyppä, J.; Kaartinen, H.; Kukko, A.; Holopainen, M. Automatic plot-wise tree location mapping using single-scan terrestrial laser scanning. Photogramm. J. Finl. 2011, 22, 37-48.

20. Lindberg, E.; Holmgren, J.; Olofsson, K.; Olsson, H. Estimation of stem attributes using a combination of terrestrial and airboner laser scanning. Eur. J. For. Res. 2012, 131, 1917-1931.

21. Raumonen, P.; Kaasalainen, M.; Åkerblom, M.; Kaasalainen, S.; Kaartinen, H.; Vastaranta, M.; Holopainen, M.; Disney, M.; Lewis, P. Fast automatic precision tree models from terrestrial laser scanner data. Remote Sens. 2013, 5, 491-520.

22. Hopkinson, C.; Chasmer, L.; Young-Pow, C.; Treitz, P. Assessing forest metrics with a ground-based scanning lidar. Can. J. For. Res. 2004, 34, 573-583.

23. Pfeifer, N.; Winterhalder, D. Modelling of tree cross sections from terrestrial laser-scanning data with free-form curves. Int. Arch. Photogramm. Remote Sens. Spat. Inf. Sci. 2004, 36, 76-81.

24. Vastaranta, M.; Melkas, T.; Holopainen, M.; Kaartinen, H.; Hyyppä, J.; Hyyppä, H. Laser-Based field measurements in tree-level forest data acquisition. Photogramm. J. Finl. 2009, 21, 51-61.

25. Liang, X.; Litkey, P.; Hyyppä, J.; Kaartinen, H.; Vastaranta, M.; Holopainen, M. Automatic stem mapping using single-scan terrestrial laser scanning. IEEE Trans. Geosci. Remote Sens. 2012, 50, 661-670.

26. Kankare, V.; Holopainen, M.; Vastaranta, M.; Puttonen, E.; Yu, X.; Hyyppä, J.; Vaaja, M.; Hyyppä, H.; Alho, P. Individual tree biomass estimation using terrestrial laser scanning. ISPRS J. Photogramm. Remote Sens. 2013, 75, 64-75.

27. Moorthy, I.; Miller, J.R.; Hu, B.; Chen, J.; Li, Q. Retrieving crown leaf area index from an individual tree using ground-based lidar data. Can. J. Remote Sens. 2008, 34, 320-332.

28. Hyyppä, J.; Jaakkola, A.; Hyyppä, H.; Kaartinen, H.; Kukko, A.; Holopainen, M.; Zhu, L.; Vastaranta, M.; Kaasalainen, S.; Krooks, A.; et al. Map updating and change detection using vehicle-based laser scanning. In Proceedings of the Urban Remote Sensing Joint Event, Shanghai, China, 20-22 May 2009.

29. Liang, X.; Kankare, V.; Yu, X.; Hyyppä, J.; Holopainen, M. Automated stem curve measurement using terrestrial laser scanning. IEEE Trans. Geosci. Remote Sens. 2014, 52, 1739-1748.

30. Maas, H.G.; Bienert, A.; Scheller, S.; Keane, E. Automatic forest inventory parameter determination from terrestrial laser scanner data. Int. J. Remote Sens. 2008, 29, 1579-1593.

31. Maltamo, M.; Peuhkurinen, J.; Malinen, J.; Vauhkonen, J.; Packalén, P.; Tokola, T. Predicting tree attributes and quality characteristics of Scots pine using airborne laser scanning data. Silva Fenn. 2009, 43, 507-521. 
32. Maltamo, M.; Bollandsås, O.M.; Vauhkonen, J.; Breidenbach, J.; Gobakken, T.; Næsset, E. Comparing different methods for prediction of mean crown height in Norway spruce stands using airborne laser scanner data. Forestry 2010, 83, 257-268.

33. Thies, M.; Pfeifer, N.; Winterhalder, D.; Gorte, B.G.H. Three-Dimensional reconstruction of stems for assessment of taper, sweep and lean based on laser scanning of standing trees. Scand. J. For. Res. 2004, 5, 571-581.

34. Kretscmer, U.; Kirchner, N.; Morhart, C.; Spiecker, H. A new approach to assessing tree stem quality characteristics using terrestrial laser scans. Silva Fenn. 2013, 47, 14.

35. Stängle, S.M.; Brüchert, F.; Kretschmer, U.; Spiecker, H.; Sauter, U.H. Clear wood content in standing trees predicted from branch scar measurements with terrestrial LiDAR and verified with X-ray CT. Can. J. For. Res. 2014, 44, 145-153.

36. Van Leeuwen, M.; Hilker, T.; Coops, N.C.; Frazer, G.; Wulder, M.A.; Newnham, G.J.; Culvenor, D.S. Assessment of standing wood and fiber quality using ground and airborne laser scanning: A review. For. Ecol. Manag. 2011, 261, 1467-1478.

37. Hilker, T.; Frazer, G.W.; Coops, N.C.; Wulder, M.A.; van Leeuwen, M.; Newnham, G.J.; Culvenor, D.S.; Stewart, J.D. Prediction of wood fiber attributes from LiDAR-derived forest canopy indicators. For. Sci. 2013, 59, 231-242.

38. Luther, J.E.; Skinner, R.; Fournier, R.A.; van Lier, O.R.; Bowers, W.W.; Coté, J.-F.; Hopkinson, C.; Moulton, T. Predicting wood quantity and quality attributes of balsam fir and black spruce using airborne laser scanner data. Forestry 2013, doi:10.1093/forestry/cpt039.

39. Vauhkonen, J.; Korpela, I.; Maltamo, M.; Tokola, T. Imputation of single-tree attributes using airborne laser scanning-based height, intensity, and alpha shape metrics. Remote Sens. Environ. 2010, 114, 1263-1276.

40. Maltamo, M.; Mehtätalo, L.; Vauhkonen, J.; Packalén, P. Predicting and calibrating tree attributes by means of airborne laser scanning and field measurements. Can. J. For. Res. 2012, 42, 1896-1907.

41. Crookston, N.L.; Finley, A.O. yaImpute: A R Package for Efficient nearest Neighbor Imputation Routines Variance Estimation, and Mapping, 2007-2010. Available online: http:// cran.r-project.org (accessed on 7 August 2013).

42. Hudak, A.; Crookston, N.; Evans, J.; Hall, D.; Falkowski, M. Nearest neighbor imputation of species-level, plot-scale forest structure attributes from LiDAR data. Remote Sens. Environ. 2008, 112, 2232-2245.

43. Falkowski, M.; Hudak, A.; Crookston, N.; Gessler, P.; Smith, A. Landscape-scale parameterization of a tree-level forest growth model: A k-NN imputation approach incorporating LiDAR data. Can. J. For. Res. 2010, 40, 184-199.

44. Team, R.D.C. R: A Language and Environment for Statistical Computing; R Foundation for Statistical Computing: Vienna, Austria, 2013. Available online: http://www.R-project.org (accessed on 2 December 2013).

45. Malinen, J.; Berg, V.; Kilpeläinen, H. Roundwood pricing mechanisms and their performance in Scots pine roundwood markets. Working Papers Finn. For. Res. Inst. 2010, 174, 35.

46. Lundgren, C. Predicting log type and knot size category using external logshape data from a 3D log scanner. Scand. J. For. Res. 2000, 15, 119-126. 
47. Oja, J.; Grundberg, S.; Fredriksson, J.; Berg, P. Automatic grading of saw logs-A comparison between Xray scanning, optical 3D scanning and combination of both methods. Scand. J. For. Res. 2004, 19, 89-95.

48. Barth, A.; Holmgren, J. Stem taper estimates based on airborne laser scanning and cut-to-length harvester measurements for pre-harvest planning. Int. J. For. Eng. 2013, 23, 161-169.

49. Vauhkonen, J.; Packalen, P.; Malinen, J.; Pitkänen, J.; Maltamo, M. Airborne laser scanning-based decision support for wood procurement planning. Scand. J. For. Res. 2014, in press.

50. Peuhkurinen, J.; Maltamo, M.; Malinen, J.; Pitkänen, J.; Packalén, P. Preharvest measurement of marked stands using airborne laser scanning. For. Sci. 2007, 53, 653-661.

51. Peuhkurinen, J.; Maltamo, M.; Malinen, J. Estimating species specific diameter distributions and saw log recoveries of boreal forests from airborne laser scanning data and aerial photographs: A distribution-based approach. Silva Fenn. 2008, 42, 625-641.

52. Murphy, G.E.; Acuna, M.A.; Dumbrell, I. Tree value and log product yield determination in radiata pine (Pinus radiata) plantations in Australia: Comparisons of terrestrial laser scanning with a forest inventory system and manual measurements. Canad. J. For. Res. 2010, 40, 2223-2233.

53. Vastaranta, M.; Saarinen, N.; Kankare, V.; Holopainen, M.; Kaartinen, H.; Hyyppä, J.; Hyyppä, H. Multisource single-tree inventory in the prediction of tree quality variables and logging recoveries. Remote Sens. 2014, 6, 3475-3491.

(C) 2014 by the authors; licensee MDPI, Basel, Switzerland. This article is an open access article distributed under the terms and conditions of the Creative Commons Attribution license (http://creativecommons.org/licenses/by/3.0/). 